\title{
Asymmetry of disciform scarring in bilateral disease when one eye is treated with radiotherapy
}

\author{
Patricia M Hart, Desmond B Archer, Usha Chakravarthy
}

\begin{abstract}
Aims/Background-A previous study has shown that in age-related macular degeneration a high degree of concordance of disciform scar size occurs in the two eyes of any one patient. In a study of 35 patients with choroidal neovascular membrane who were treated with low dose ionising radiation to the macula of the affected eye, 11 were found to have bilateral disease.

Methods-The visual outcome and scar size and morphology in the two eyes of each of these patients were compared.

Results-In all radiotherapy treated eyes the appearance of the scar ranged from subtle subretinal pigmentary changes to dense subretinal fibrosis. By contrast all untreated fellow eyes showed marked subretinal scarring. Scars in radiotherapy treated eyes occupied an area that was approximately one third of that in untreated fellow eyes $\left(3.8 \mathrm{~mm}^{2} v\right.$ $11.7 \mathrm{~mm}^{2}$ ). Distance and near visual acuities in radiotherapy treated eyes were significantly better than that of untreated fellow eyes $(\mathbf{p}<0.0033)$. Although untreated fellow eyes of necessity had longer follow up periods ( 64.5 months), the mean follow up time in treated eyes was 28 months by which time the disciform response is generally thought to have ceased evolving.

Conclusion-This study has provided evidence in support of reduced scarring and maintenance of better central visual function in radiotherapy treated eyes when compared with untreated fellow eyes.

(Br f Ophthalmol 1995; 79: 562-568)
\end{abstract}

Age-related macular degeneration (ARMD) complicated by choroidal neovascular membranes (CNVM) is associated with a very poor visual prognosis. ${ }^{1}$ The majority of CNVM at initial presentation have some degree of foveal involvement and the predilection of CNVM to grow towards the fovea is well documented. ${ }^{2}$ Laser photocoagulation remains the mainstay of treatment for extrafoveal CNVM, however, when used in the treatment of subfoveal disease it results in a significant and immediate drop in acuity and any visual benefit does not become evident until 18 months. ${ }^{3}$ This treatment option therefore is unacceptable to most ARMD sufferers and many ophthalmologists. Furthermore it has been shown that patients with exudative ARMD in one eye develop active disease in the fellow eye at a rate of $12 \%$ to $15 \%$ per year. ${ }^{4}$ When visual acuity in the first affected eye is already severely compromised, foveal ablation of the CNVM in the second eye by laser is even more likely to be rejected. Patients often find it difficult to accept a marginal visual benefit in the long term at the cost of a profound and immediate visual loss in their only seeing eye. Understandably, alternative treatment methods are being sought.

We have previously shown in a pilot study comprising 19 patients with subfoveal CNVM that focal radiotherapy resulted in the stabilisation and maintenance of central visual function during an average follow up time of 1 year. ${ }^{5}$ We now have data on 35 patients who received radiotherapy for subfoveal neovascular membranes. As we regularly reviewed these patients it became evident that, in general, the disciform scars in eyes treated with radiation were smaller and/or less dense than those seen in the untreated fellow eyes. Since a high degree of concordance of scar size in the two eyes of any patient affected with CNVM has been shown, ${ }^{6}$ we identified all patients with bilateral involvement from within our 35 study patients and retrospectively compared visual outcome, scar size, and

Table 1 Patient details

Department of Ophthalmology, Queen's University of Belfast, Belfast, Northern Ireland P M Hart D B Archer U Chakravarthy

Correspondence to: Miss Usha Chakravarthy, Department of Ophthalmology, Queen's University of Belfast, Royal Victoria Hospital, Belfast BT12 6BA, Northern Ireland.

Accepted for publication 2 February 1995

\begin{tabular}{|c|c|c|c|c|c|c|c|c|c|c|}
\hline $\begin{array}{l}\text { Ref } \\
n o\end{array}$ & $\begin{array}{l}\text { Age } \\
\text { (years) }\end{array}$ & $\begin{array}{l}F U T \\
S E\end{array}$ & $\begin{array}{l}F U T \\
F E\end{array}$ & $\begin{array}{l}\text { Init } V A \\
S E\end{array}$ & $\begin{array}{l}\text { Final } V A \\
S E\end{array}$ & $\begin{array}{l}\text { Final VA } \\
F E\end{array}$ & $\begin{array}{l}\text { Final NV } \\
S E\end{array}$ & $\begin{array}{l}\text { Final NV } \\
F E\end{array}$ & $\begin{array}{l}\text { Scar } \\
\left(m m^{2}\right) S E\end{array}$ & $\begin{array}{l}\text { Scar } \\
\left(\mathrm{mm}^{2}\right) F E\end{array}$ \\
\hline $\begin{array}{c}1 \\
2 \\
3 \\
4 \\
5 \\
6 \\
7 \\
8 \\
9 \\
10 \\
11 \\
\text { Mean } \\
\text { SD }\end{array}$ & $\begin{array}{c}82 \\
76 \\
80 \\
70 \\
81 \\
84 \\
79 \\
69 \\
76 \\
69 \\
84 \\
77 \\
5 \cdot 7\end{array}$ & $\begin{array}{c}36 \\
12 \\
36 \\
20 \\
24 \\
40 \\
30 \\
20 \\
36 \\
36 \\
18 \\
28 \\
9 \cdot 5\end{array}$ & $\begin{array}{r}44 \\
100 \\
48 \\
48 \\
40 \\
64 \\
100 \\
32 \\
90 \\
100 \\
44 \\
64 \cdot 5 \\
27 \cdot 3\end{array}$ & $\begin{array}{l}7 \\
6 \\
8 \\
2 \\
3 \\
1 \\
7 \\
7 \\
7 \\
8 \\
7 \\
5 \cdot 7 \\
2 \cdot 6\end{array}$ & $\begin{array}{l}6 \\
7 \\
9 \\
3 \\
5 \\
2 \\
8 \\
7 \\
8 \\
8 \\
6 \\
6 \cdot 27 \\
2 \cdot 2\end{array}$ & $\begin{array}{l}1 \\
0.5 \\
0.5 \\
0.5 \\
2 \\
1 \\
0.5 \\
2 \\
3 \\
0.5 \\
0.5 \\
1.09 \\
0.9\end{array}$ & $\begin{array}{l}3 \\
3 \\
6 \\
4 \\
4 \\
3 \\
2 \\
5 \\
5 \\
5 \\
3 \\
3 \cdot 9 \\
1 \cdot 2\end{array}$ & $\begin{array}{l}1 \\
1 \\
1 \\
1 \\
2 \\
1 \\
1 \\
1 \\
1 \\
1 \\
1 \\
1 \cdot 09 \\
0 \cdot 3\end{array}$ & $\begin{array}{l}3.52 \\
5.65 \\
7.36 \\
3.45 \\
1.12 \\
7.51 \\
1.51 \\
2.14 \\
6.62 \\
1.81 \\
1.37 \\
3.82 \\
2.5\end{array}$ & $\begin{array}{r}5.61 \\
10.85 \\
23.12 \\
11.88 \\
10.58 \\
7.87 \\
12.49 \\
11.01 \\
14.74 \\
13.91 \\
6.83 \\
11.7 \\
5.0\end{array}$ \\
\hline
\end{tabular}

Distance visual acuity (VA): $\mathrm{CF} / \mathrm{HM}=0 \cdot 5,1 / 60=1,2 / 60=2,3 / 60=3,4 / 60=4,5 / 60=5,6 / 60=6,6 / 36=7,6 / 24=8,6 / 18=9$. Near visual acuity $(\mathrm{NV}):<\mathrm{N} 48=1, \mathrm{~N} 48=2, \mathrm{~N} 36=3, \mathrm{~N} 24=4, \mathrm{~N} 18=5, \mathrm{~N} 14=6$.

$\mathrm{SE}=$ study eye; $\mathrm{FE}=$ fellow eye; $\mathrm{FUT}=$ follow up time. 

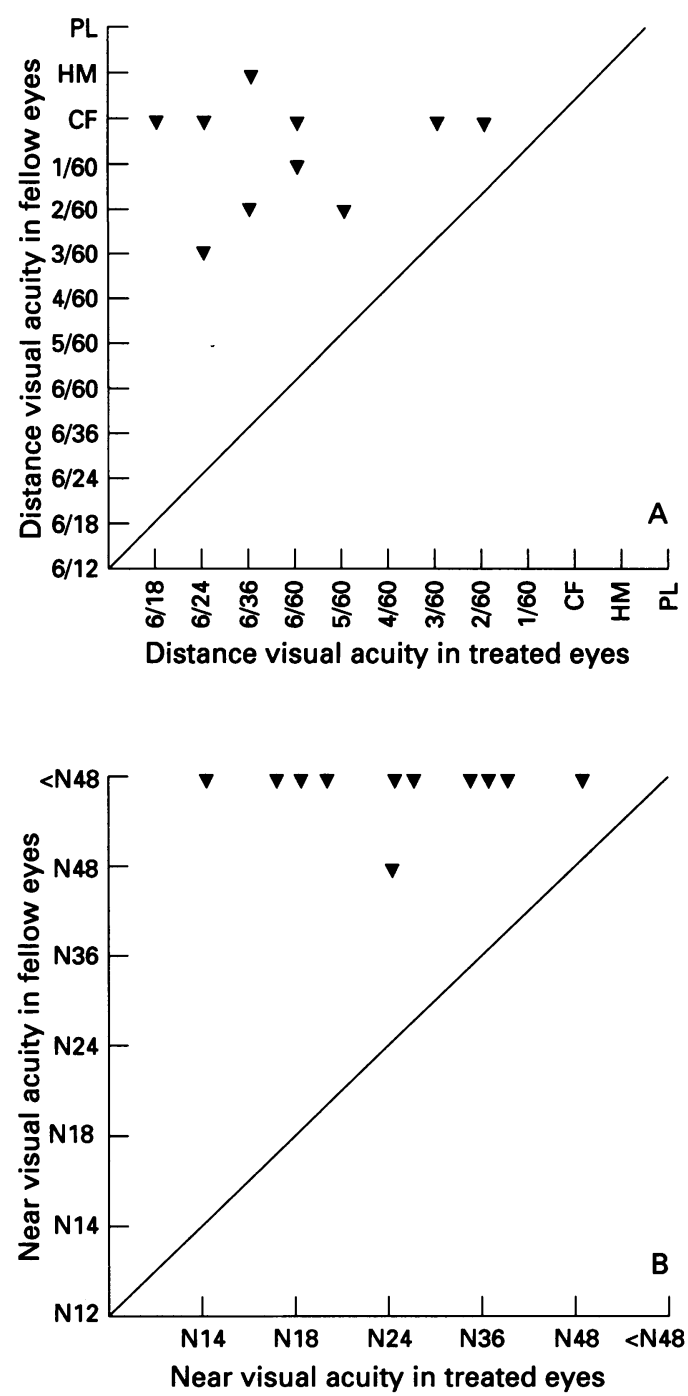

Figure 1 (A) Correlation between distance visual acuity in treated and untreated eyes. Treated eyes show better acuity than untreated eyes. (B) Correlation between near acuity in treated and untreated eyes. Treated eyes show better acuity than untreated fellow eyes.

morphology in the treated eye versus the untreated fellow eye.

\section{Methods}

Forty seven patients with subfoveal neovascular membranes diagnosed on the basis of fluorescein angiography were offered radiotherapy and 35 accepted. The ophthalmic examination included slit-lamp biomicroscopy, fully corrected distance and near visual acuity, and reading speed if the patient was able to read N48 print size or smaller. The patients were fully counselled on the nature of their condition and treatment options available, and only then was informed consent to participate in the radiotherapy trial obtained.

The results of the pilot study giving details of the radiotherapy protocol and treatment schedule have already been described. ${ }^{5}$ In brief, the patient was fitted with a custom made beam direction shell and a computed tomography scan was performed. Treatment plans were generated and prescribed to the $90 \%$ isodose which encompassed the macula of the affected eye. After radiotherapy the patients were reviewed at $3,6,12,18,24$ months, and then yearly. Visual function was assessed at every visit and angiography scheduled for the $3,6,12$, and 24 month visits.

Thirteen patients had bilateral ARMD and in each case the eye which received radiotherapy was the second eye to be involved. Two of these patients had undergone unsuccessful laser photocoagulation to the study eye before radiotherapy and were therefore excluded. Ten patients had a follow up of between 18 and 40 months and one patient 12 months. In these patients, the primary outcome variables which were subjected to analysis were visual acuity and scar size and density assessed on colour fundus photographs. Best corrected distance visual acuity on the Snellen chart was recorded. Near reading acuity was measured using the Keeler test types at $25 \mathrm{~cm}$ with the reading correction added to the distance refraction. Low vision aids were not employed. Image analysis was carried out in a masked fashion by an independent observer on an IBM compatible PC using standard software (Fenestra, Confocal Technologies, UK). Colour transparencies of the macular region of each eye of each patient were coded and monochromatic images captured through a camera system linked to a frame grabber and then analysed using two different techniques. To obtain scar area measurements we initially quantified the dense fibrous tissue within the scar using the threshold function in the software which identifies whiter areas within the image. However, in some cases (for example, Figures $2 \mathrm{~d}$ and $5 \mathrm{~b}$ ) regions with excessive pigmentation were not recognised as part of the scar. We therefore also measured each scar by outlining the area of disciform scarring using a hand held mouse, and in Figures $2 \mathrm{~d}$ and $5 \mathrm{~b}$ this result was taken as scar area. In some cases - for example, Figure 4a, this latter method was not possible as a discrete scar was not present. In all cases at least one method could be performed with confidence.

\section{STATISTICAL ANALYSIS}

Visual acuity data were analysed using the Wilcoxon matched pairs signed ranks test. Scar size measurements were analysed using Student's $t$ test for paired samples.

\section{Results}

Patient details are given in Table 1. The mean follow up time of the study eye was $28 \cdot 0$ (SD 9.5) months from treatment. Although accurate dating of disease onset in the fellow eye was not available in all cases, all patients were able to provide a rough estimate of the duration of visual loss in these eyes. The mean duration of disciform disease in fellow eyes was $64 \cdot 5(27 \cdot 3)$ months. The visual acuity outcome for study and fellow eyes is listed in Table 1. Within the bilateral subgroup, eyes treated with radiotherapy showed an average improvement of 0.57 lines on the Snellen chart from baseline at their last visit. This was 

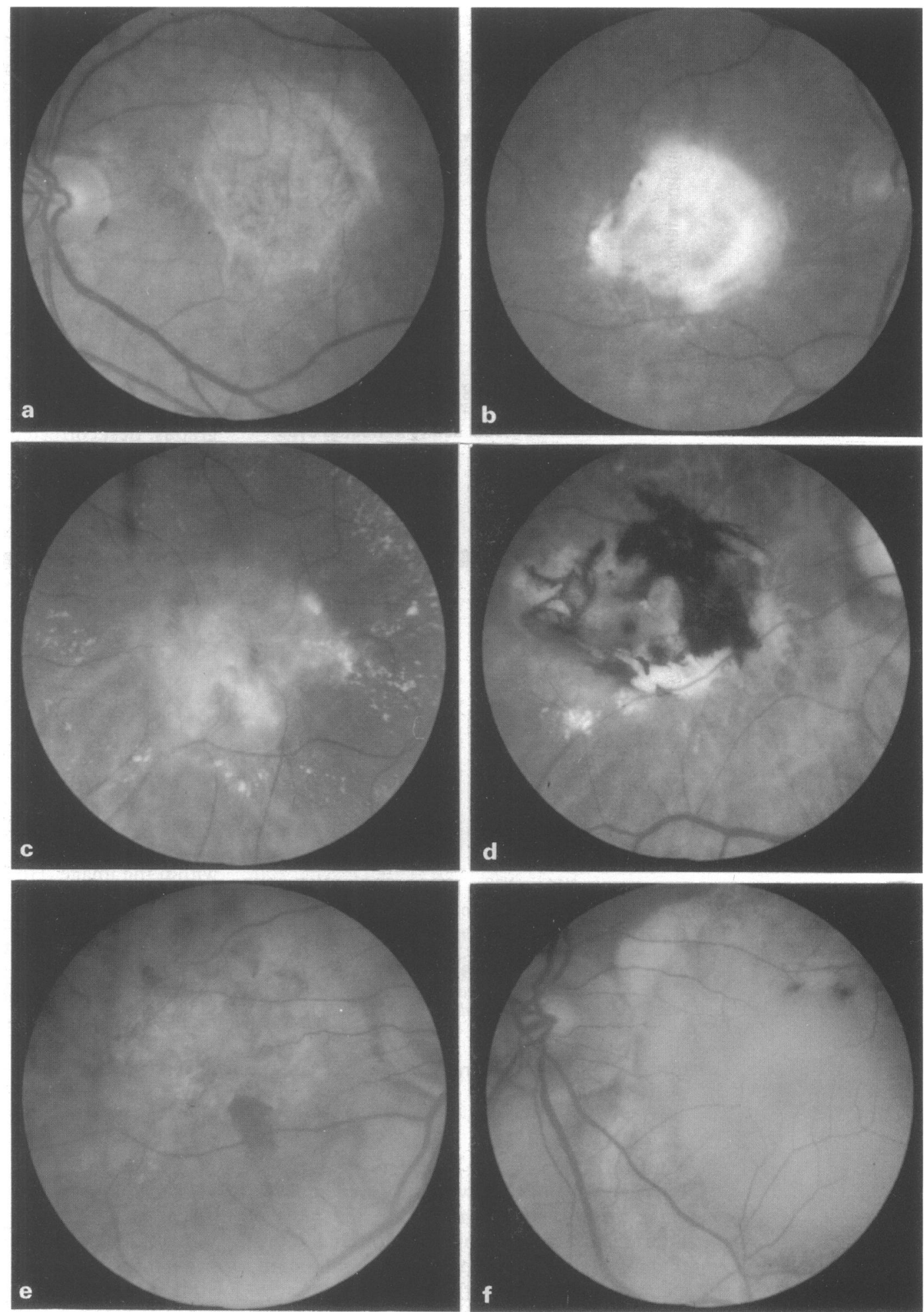

Figure 2 (a) and (b) Fundus photographs of patient 1. (a) Treated left eye with visual acuity of $6 / 60$ showing translucent scar 36 months after radiation. (b) Untreated fellow eye 44 months after onset of disease with a visual acuity of $1 / 60$ showing densely fibrotic macular scar. (c) and (d) Fundus photographs of patient 2 . (c) Treated left eye 12 months after radiotherapy with a visual acuity of 6/36 showing poorly defined disciform scar. (d) Untreated fellow eye 100 months after onset of disease with a visual acuity of counting fingers showing densely fibrotic pigmented scar. $(e)$ and $(f)$ Fundus photographs of patient 3 . (e) Treated right eye 36 months after radiation with minimal scarring. $(f)$ Untreated fellow eye 48 months after onset of disease with a visual acuity of counting fingers and extensive macular scarring.

consistent with the overall trend in acuity seen within the entire study population of 35 patients. No baseline visual acuity was available for fellow eyes. The mean distance visual acuity of study eyes at their last visit lay between $6 / 36$ and $6 / 60$ and that of fellow eyes between $2 / 60$ and $1 / 60(p<0 \cdot 0033)$. The mean near visual acuity of study eyes at their last visit was N24 and that of fellow eyes N48 $(p<0.0033)$. The concordance in distance and near visual acuity between treated and fellow eyes is shown in Figure 1.

In treated eyes the appearance of the macula ranged from subtle subretinal pigmentary changes without scarring to densely opaque fibrotic scars (Figures 2a to 5c). In all untreated eyes a definite scar was evident and the appearance varied from translucent subretinal fibrous tissue with retinal pigment epithelial atrophy to opaque and densely 

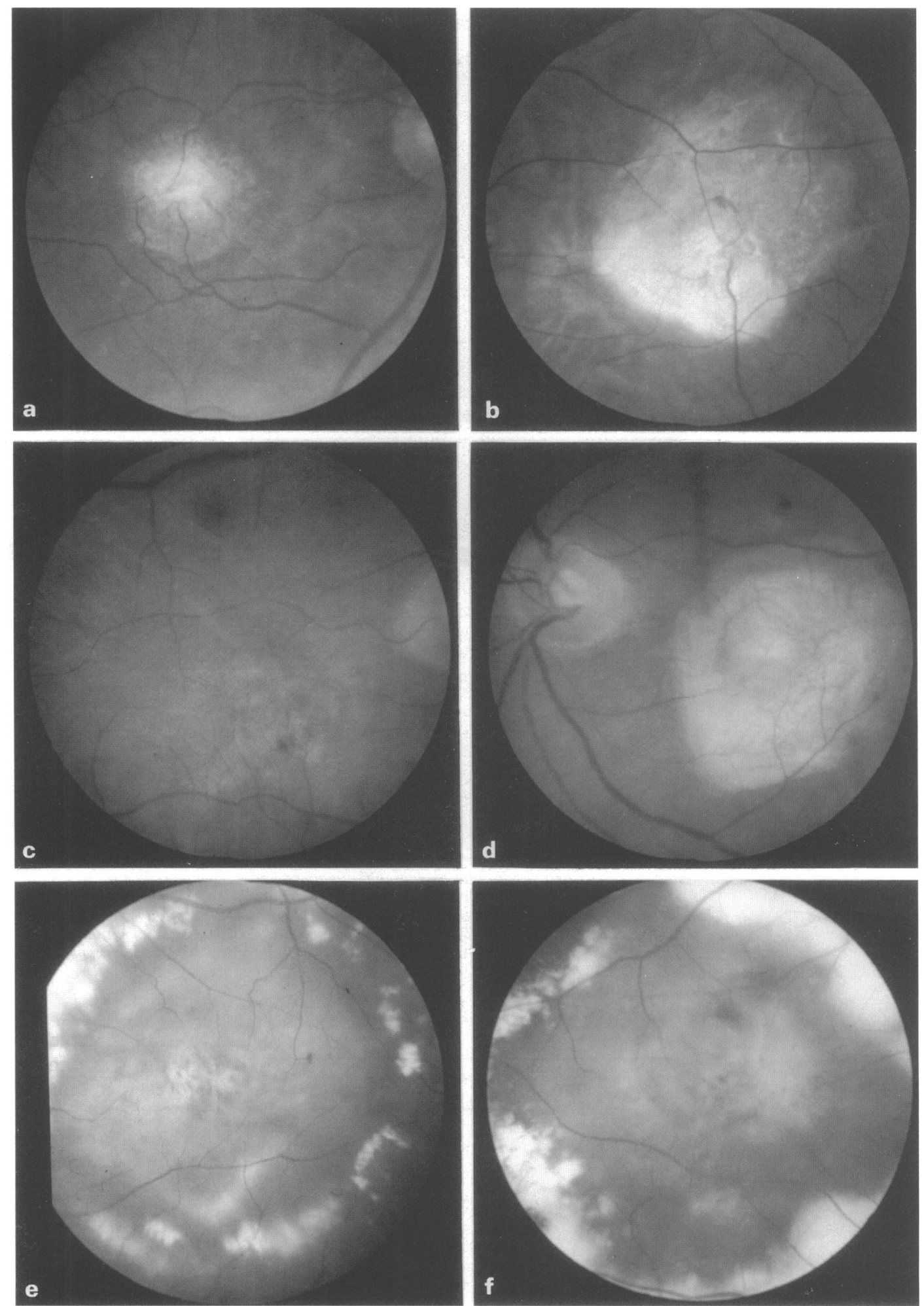

Figure 3 (a) and (b) Fundus photograph of patient 4. (a) Treated right eye 20 months after radiation with a visual acuity of 3/60 showing well defined central macular scar. (b) Untreated fellow eye 48 months after disease onset and a visual acuity of counting fingers showing more extensive scarring. (c) and (d) Fundus photographs of patient 5. (c) Treated right eye 24 months after radiotherapy with visual acuity of 5/60 showing pigmentary disturbance and some haemorrhage but no scarring. (d) Untreated fellow eye 40 months after onset of disease with visual acuity of 2/60 with subretinal fibrosis. (e) and ( $f$ ) Fundus photographs of patient 6. (e) Treated left eye, 40 months after radiotherapy with a visual acuity of 2/60 showing extensive disciform response with exudation. (f) Untreated fellow eye 64 months after disease onset with visual acuity of $1 / 60$ showing extensive exudation and scarring.

fibrotic scars involving the entire thickness of the retina, with or without pigmentation (Figures $2 \mathrm{~b}$ to $5 \mathrm{~d}$ ). The mean area of scars in treated eyes was $3.82(2.5) \mathrm{mm}^{2}$ and that of untreated fellow eyes $11 \cdot 7$ (5) $\mathrm{mm}^{2}$ $(p<0.0001)$. The mean ratio of final scar size of the treated eye to the fellow eye was $0 \cdot 30$. The correlation between final scar size in treated and untreated eyes is shown in Figure 6. Where both freehand outlining of the scar and thresholding were possible the results for each scar showed a high degree of concordance (Table 2) in all but one patient. In this patient (Figures 2a and b) scars of similar area were present in each eye but the intensity of fibrosis differed markedly. Fundus photographs of patient 11 are not shown as they were of poor quality owing to lens opacification. 

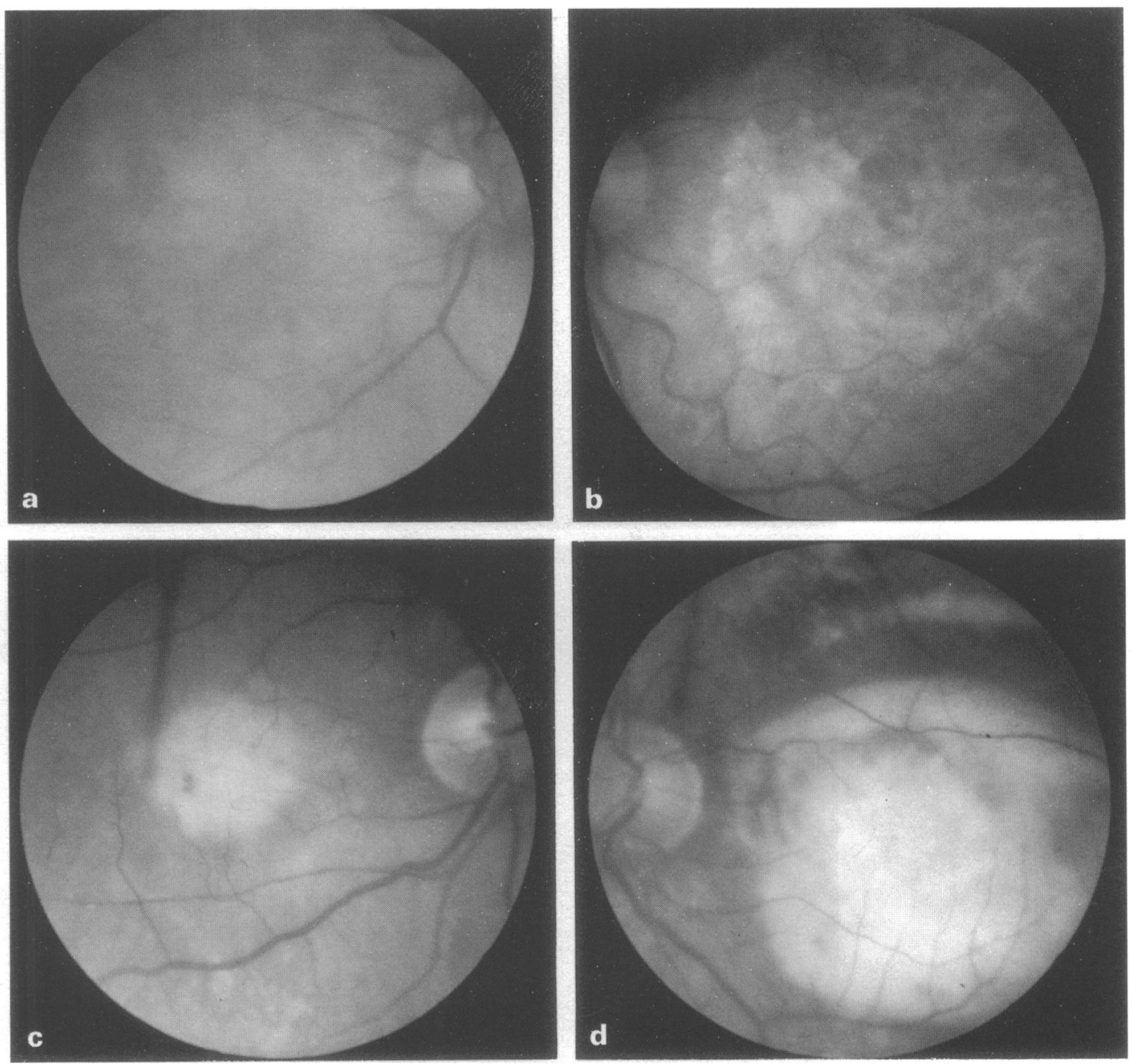

Figure 4 (a) and (b) Fundus photographs of patient 7. (a) Treated right eye, 30 months after radiation with visual acuity of 6/24 showing no disciform response. (b) Untreated fellow eye 100 months after onset of disease with visual acuity of counting fingers with subretinal scarring. (c) and (d) Fundus photographs of patient 8. (c) Treated right eye 20 months after radiotherapy with visual acuity of 6/36 showing clearly demarcated subretinal scar (d) Untreated fellow eye

32 months after disease onset with visual acuity of 2/60 showing extensive scarring of the macular region.

Table 2 Scar area in treated and fellow eyes measured by image analysis

\begin{tabular}{|c|c|c|}
\hline $\begin{array}{l}\text { Serial } \\
\text { no. }\end{array}$ & $\begin{array}{l}\text { Freehand area } \\
\left(\mathrm{mm}^{2}\right)\end{array}$ & $\begin{array}{l}\text { Thresholded area } \\
\left(\mathrm{mm}^{2}\right)\end{array}$ \\
\hline $1 a$ & $6 \cdot 1$ & 3.52 \\
\hline $1 \mathrm{~b}$ & 5.65 & $5 \cdot 61$ \\
\hline $2 a$ & 5.65 & $5 \cdot 35$ \\
\hline $2 b$ & $10 \cdot 85$ & - \\
\hline $3 a$ & $6 \cdot 18$ & $7 \cdot 36$ \\
\hline $3 b$ & $22 \cdot 14$ & $23 \cdot 12$ \\
\hline $4 a$ & 3.38 & $3 \cdot 45$ \\
\hline $4 \mathrm{~b}$ & 11.04 & $11 \cdot 88$ \\
\hline $5 a$ & 0.95 & $1 \cdot 12$ \\
\hline $5 \mathrm{~b}$ & $10 \cdot 11$ & 10.58 \\
\hline $6 a$ & $7 \cdot 52$ & $7 \cdot 51$ \\
\hline $6 \mathrm{~b}$ & $7 \cdot 98$ & $7 \cdot 87$ \\
\hline $7 a$ & - & 1.51 \\
\hline $7 \mathrm{~b}$ & $12 \cdot 49$ & $18 \cdot 1$ \\
\hline $8 a$ & 1.93 & $2 \cdot 14$ \\
\hline $8 b$ & $10 \cdot 8$ & $11 \cdot 01$ \\
\hline $9 a$ & $6 \cdot 62$ & $7 \cdot 3$ \\
\hline $9 b$ & $14 \cdot 74$ & - \\
\hline $10 a$ & 1.67 & $1 \cdot 81$ \\
\hline $10 \mathrm{~b}$ & 13.73 & 13.91 \\
\hline $11 \mathrm{a}$ & $1 \cdot 15$ & 1.37 \\
\hline $11 \mathrm{~b}$ & $6 \cdot 73$ & $6 \cdot 83$ \\
\hline
\end{tabular}

Serial numbers refer to patients 1 to 11 .

$a=$ study eye and $b=$ fellow eye.

\section{Discussion}

Symmetry of disciform scarring in bilateral age-related CNVM has previously been demonstrated. 6 Concordance in scar size between the two eyes of untreated patients was found to be highest when the duration of disease was at least 12 months in the second eye to be affected. ${ }^{6}$ This observation implies that the morphological appearance of the fibrovascular scar does not change substantially after 12 months from initial presentation. Furthermore, Lavin et al also found that the time of presentation did not influence subsequent scar size - that is, the first affected eye did not have a tendency towards larger or smaller scars. ${ }^{6}$ The present study has shown that when there is bilateral involvement the disparity in outcome in terms of visual acuity and macular morphology between radiotherapy treated eyes and untreated fellow eyes is striking and suggests that this treatment modality alters the expected outcome. The scars in treated eyes occupied a smaller area, were less fibrotic in appearance, and in some cases were identifiable only as a diffuse outer retinal disturbance. Visual acuity too was significantly better when compared with fellow eyes and this is in accordance with previous studies which have shown that final visual acuity is closely related to scar size. ${ }^{7}$

While we have shown statistical and pictorial evidence for loss of symmetry in terms of scar size when one eye is treated with radiotherapy, the appearance of the scars in some eyes 

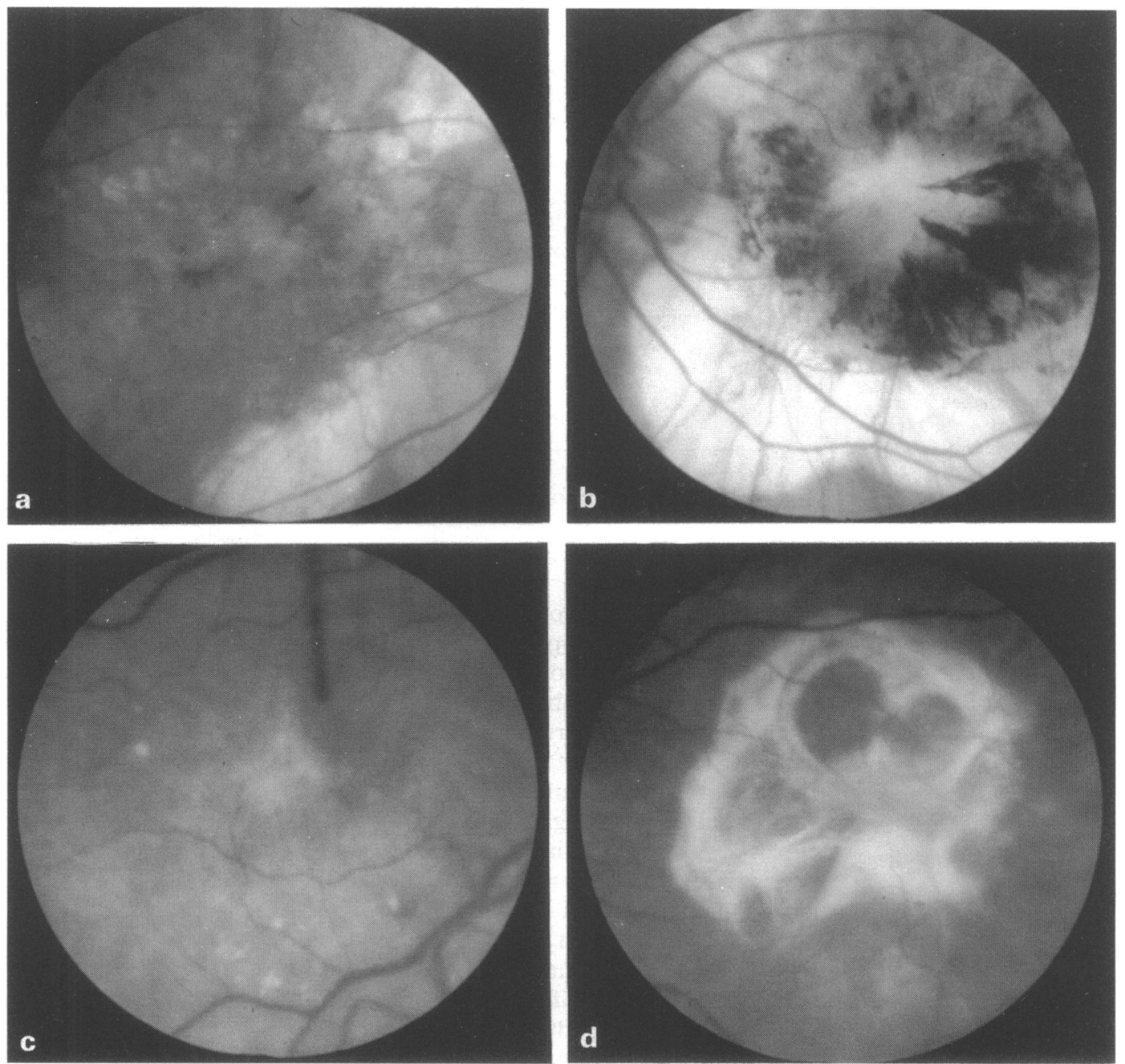

Figure 5 (a) and (b) Fundus photographs of patient 9. (a) Treated right eye 36 months after radiation with visual acuity of 6/24 showing pigmentation around the fovea, subretinal scarring and atrophy of the retinal pigment epithelium. (b) Untreated fellow eye 90 months after onset of disease with visual acuity of 5/60 showing severe pigment hyperplasia, extensive atrophy, and marked fibrosis. (c) and (d) Fundus photographs of patient 10. (c) Treated right eye 36 months after radiotherapy with visual acuity of 6/24 showing minimal subretinal scanning. (d) Untreated fellow eye 100 months after disease onset with visual acuity of counting fingers and marked subretinal fibrosis.

continued to show similar characteristics. The shape and size of the scar in each eye of patient 1 were similar although the density of fibrous tissue was markedly different. Untreated eyes in patients 2 and 9 showed a marked retinal pigment epithelial hyperplasia while the treated eyes of both these patients also showed pigment hyperplasia but to a lesser extent. When viewed by an independent observer, photographs of treated eyes of patients 4,8 , and 10 were initially thought to represent photographs of the corresponding fellow eyes but taken at a lower magnification. The implication from these observations was that the overall morphology was not dissimilar between the two eyes, but that in treated eyes the appearance was that of a muted version of the florid scar tissue response seen in the fellow eye. Our results therefore would also support the premise that factors common to both eyes are important in the morphogenesis of a disciform scar.

It has been recognised over the past two decades that ARMD is essentially a bilateral condition although the manifestations of the disease in each eye may be temporally separated. ${ }^{8}$ Various studies have identified genetic, ${ }^{9}$ systemic, and environmental risk factors for the development of ARMD. ${ }^{10}$
Associations have been shown between the presence of CNVM and higher white blood cell count and extent of dermal elastotic degeneration in sun protected dermis. ${ }^{11}$ Thus, all risk factors so far identified would influence both eyes equally and it is not surprising therefore that considerable symmetry exists between the two eyes of any individual with ARMD. Those variables previously shown to display symmetry are type and extent of drusen, ${ }^{12}$ retinal pigment epithelial rips, ${ }^{13}$ and disciform scars. ${ }^{6}$ In addition the presence of a large disciform scar in the first eye has been suggested as predictive of the final outcome in the second eye with regard to visual acuity and risk of recurrence of CNVM following laser photocoagulation. ${ }^{14}$ Thus the presence of a large disciform scar in the first eye is often an incentive to offer radical treatment such as foveal ablation in an attempt to minimise scotoma size when a CNVM is present in the fellow eye.

The exact nature of the angiogenic stimulus in CNVM remains unclear although it appears to be related to the nature and quantity of accumulated drusen material. ${ }^{15}$ An inflammatory component is invariably seen in association with a CNVM and is thought to play a role in the development of the membrane. ${ }^{16}$ An increased 
Figure 6 Lack of concordance in scar size between treated and untreated eye is shown. Eyes treated with radiotherapy demonstrated smaller scar as seen by the clustering of data points to the left of the line of symmetry.

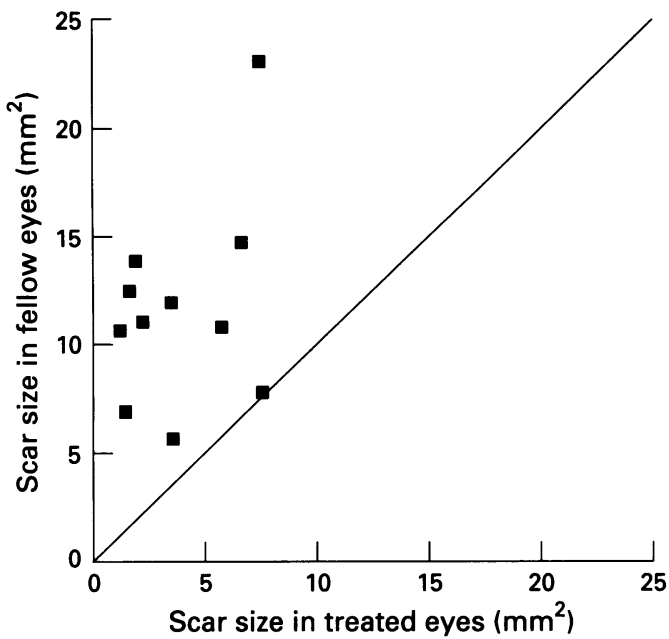

number of monocytes and lymphocytes has been reported in the choroidal vasculature and stroma of eyes from patients with macular degeneration and is thought to contribute to breaks in Bruch's membrane. ${ }^{17}$ In many ways the evolving disciform response resembles the granulation tissue of healing wounds. $^{16}$ Advances in the identification of cytokines which regulate pathological processes such as neoplasia, wound healing, angiogenesis, and fibrosis have prompted new approaches to the management of CNVM - for example, $\alpha$ interferon. ${ }^{18}$ We have shown in an animal model of perforating ocular injuries that focal radiotherapy limits the proliferation of granulation tissue and markedly reduces inflammatory cell recruitment. ${ }^{19}$ We believe radiotherapy acts to minimise size and intensity of the disciform response through several pathways. Firstly, the proliferation of endothelial cells within the CNVM would be arrested by low doses of ionising radiation and ultimately result in mitotic death of these cells. Secondly, through its attenuating effects on the inflammatory response the stimulus for the formation of a large disciform scar is reduced. This is in contrast with the scenario following laser photocoagulation where tissue destruction and the outpouring of cytokines could influence further neovascularisation possibly even contributing to the high incidence of recurrences. There was considerable variation in visual outcome and final scar morphology in treated patients as the disciform response at the time of therapy was at varying stages of evolution - in many instances it was already established.

Currently laser photocoagulation is the only treatment option available to patients with clearly defined subfoveal choroidal neovascularisation which fit the Macular Photocoagulation Study Group criteria for foveal ablation. ${ }^{3}$ A recent report from the Macular Photocoagulation Study Group examined the influence of initial lesion size and acuity on visual outcome after foveal ablation. ${ }^{20}$ This report suggested that patients with small lesions and moderate to poor acuity or medium lesions with poor acuity fared best with regard to visual outcome, leading to the recommendation that foveal ablation should be limited to eyes that fit these criteria. ${ }^{20}$ Even in these patients, however, the Macular Photocoagulation Study Group report shows that there is significant loss of visual acuity observed between baseline and 3 months which is directly attributable to the treatment. ${ }^{20}$ In practice, therefore, even fewer patients are suitable for foveal ablation according to current Macular Photocoagulation Study Group guidelines and the majority of patients with foveal involvement are deemed untreatable. We believe that radiotherapy has a positive treatment effect and is a reasonable alternative to laser photocoagulation. A randomised controlled study to test its efficacy is under way.

The authors gratefully acknowledge the support of the Welcome Trust and the statistical advice of $\mathrm{Dr}$ Gilbert Makenzie, Department of Epidemiology, Queen's University of Belfast.

1 Ferris FL, Fine SL, Hyman L. Age-related macular degeneration and blindness due to neovascular maculopathy. Arch Ophthalmol 1984; 102: 1640-2.

2 Bressler NM, Bressler SB, Gragoudas EG. Clinical characteristics of choroidal neovascular membranes. Arch Ophthalmol 1987; 105: 209-13.

3 Macular Photocoagulation Study Group. Laser photocoagulation of subfoveal neovascular lesions in age-related coagulation of subfoveal neovascular lesions in age-related

4 Gregor Z, Bird AC, Chisholm IH. Senile disciform macular degeneration in the second eye. Br $\mathcal{F}$ Ophthalmol 1977; 61: 141-7.

5 Chakravarthy U, Houston RF, Archer DB. Treatment of age-related subfoveal neovascular membranes by 265-73.

6 Lavin MJ, Eldem B, Gregor ZJ. Symmetry of disciform scars in bilateral age-related macular degeneration. scars in bilateral age-related

7 Weiter J, Wing GL, Trempe CL, Mainster MA. Visual acuity related to retinal distance from the fovea in macular disease. Ann Ophthalmol 1984; 16: 174-6.

8 Gass JDM. Drusen and disciform macular detachment and degeneration. Arch Ophthalmol 1973; 90: 206-17.

9 Piguet B, Wells JA, Palmvang IB, Wormwald R, Chisholm IH, Bird AC. Age-related Bruch's membrane change: a clinical study of the relative role of heredity and environment. Br f Ophthalmol 1993; 77: 400-3.

10 Leibowitz HM, Krueger DE, Maunder LR, Milton RC, Kini MM, Kahn HA, et al. The Framingham eye study monograph; an ophthalmological and epidemiological study of cataract, glaucoma, diabetic retinopathy, macular study of cataract, glaucoma, diabetic retinopathy, macular degeneration and visual acuity in a general popu
2631 adults. Surv Ophthalmol 1980; 24: 343-65.

11 Blumenkranz MS, Russell SR, Robey NG, KottBlumenkranz R, Penneys N. Risk factors in age-related maculopathy. Ophthalmology 1986; 93: 552-7.

12 Coffrey AJH, Brownstein S. The prevalence of macular drusen in post-mortem eyes. Am f Ophthalmol 1986; 102: 164-71.

13 Chuang E, Bird AC. Bilaterality of tears of retinal pigment epithelium. Br $\mathcal{F}$ Ophthalmol 1988; 72: 918-20.

14 Jalkh AE, Avila MP, Trempe CL, McMeel W, Schepens CL. Choroidal neovascularisation in fellow eyes of patients with advanced senile macular degeneration. Arch Ophthalmol 1983; 101: 1194-7.

15 Sarks SA. New vessel formation beneath the retinal pigment epithelium in senile eyes. $\mathrm{Br} \mathcal{F}$ Ophthalmol 1973; 57: 951-65.

16 Grossniklaus HE, Martinez JA, Brown VB, Lambert HM, Sternberg $\mathrm{P}$, Capone A, et al. Immunohistochemical and histochemical properties of surgically excised sub-retinal neovascular membranes in age-related macular degeneration. Am ₹ Ophthalmol 1992;114: 464-72.

17 Penfold PL, Killingsworth MC, Sarks SH. Senile macular degeneration: the involvement of immunocompetent cells. Graefes Arch Clin Exp Ophthalmol 1985; 223: 69-76.

18 Gillies MC, Sarks JP, Beaumont PE, Hunyor AB, McKay $\mathrm{D}$, Kearns $\mathrm{M}$, et al. Treatment of choroidal neovascularisation in age-related macular degeneration with interferon $\alpha 2 \mathrm{a}$ and $\alpha$ 2b. Br $\mathcal{f}$ Ophthalmol 1993; 77: $759-65$.

19 Chakravarthy U, Gardiner TA, Archer DB, Maguire CJF. A light microscopic and autoradiographic study of nonirradiated and irradiated ocular wounds. Curr Eye Res 1989; 8: $337-48$.

20 Macular Photocoagulation Study Group. Visual outcome after laser photocoagulation for sub-foveal choroidal neoafter laser photocoagulation for sub-foveal choroidal neovascular secondary to age-related macular degeneration. Arch Ophthalmol 1994; 112: 480-8. 